\begin{tabular}{l|c|c}
\hline $\begin{array}{c}\text { ISSN 2525-4812 (versão online) } \\
\text { ISSN 2238-7641 (versão impressa) } \\
\text { http://www.revistaterceiramargem.com/ } \\
\text { index.php/terceiramargem/index }\end{array}$ & $\begin{array}{c}\text { Recebido em: 3/10/2019 } \\
\text { Aprovado em: 17/5/2020 } \\
\text { Período de publicação: jan., 2021 }\end{array}$ & $\begin{array}{c}\text { Revista Terceira } \\
\text { Margem Amazônia } \\
\text { (v. 6•n. especial 16 • Jan. 2021) }\end{array}$ \\
\hline Como citar o artigo: \\
$\begin{array}{l}\text { MOREIRA, E. S.; LOPES, A. R.; DELLABIGLIA, M. D.; OLIVEIRA, A. L. A.; ROBOREDO, D. Rede de sementes do Portal } \\
\text { da Amazônia (RSPA): da coleta de sementes às contribuições aos serviços ambientais. Revista Terceira Margem Amazônia. v. }\end{array}$ \\
\begin{tabular}{l} 
6, n. especial 16, p. 177-189, 2021. DOI: http://dx.doi.org/10.36882/2525-4812.2021v6i16.ed.esp.p177-189 \\
\hline
\end{tabular}
\end{tabular}

\title{
REDE DE SEMENTES DO PORTAL DA AMAZÔNIA (RSPA): DA COLETA DE SEMENTES ÀS CONTRIBUIÇÕES AOS SERVIÇOS AMBIENTAIS
}

\author{
Edmar Santos Moreiral \\ Anderson Rogério Lopes ${ }^{2}$ \\ Márcio Dutra Dellabiglia ${ }^{3}$ \\ Ana Luisa Araújo de Oliveira \\ Delmonte Roboredo
}

\begin{abstract}
Resumo: As sementes agrícolas e florestais podem ser consideradas o principal recurso para a implantação de sistemas agroflorestais (SAFs), que contribuem para a geração de renda aos agricultores/coletores por meio da comercialização das sementes e implantação de sistemas mais diversificados que, além da geração de produtos como a madeira, fibras, sementes, alimentos, aproxima da natureza coletores e suas famílias, valorizando a floresta no contexto econômico e social, favorecendo a manutenção da biodiversidade. Com o propósito de fomentar a implantação de projeto de Sistemas Agroflorestais em municípios da região norte de Mato Grosso, em 2010 foi criada a Rede Sementes do Portal da Amazônia (RSPA). Este artigo tem como objetivos apresentar e analisar o trabalho que a RSPA vem desenvolvendo na região norte do estado de Mato Grosso. Como resultado constatou-se que a RSPA contribui direta e indiretamente para
\end{abstract}

\footnotetext{
1 Acadêmico do curso Bacharelado em Engenharia Florestal, Universidade do Estado de Mato Grosso (Unemat), Cuiabá, MT. E-mail: edmar.moreira@unemat.br

(iD) https://orcid.org/0000-0001-6493-3975

2 Engenheiro-agrônomo, responsável técnico da Rede de Sementes do Portal da Amazônia (RSPA), Cuiabá, MT. E-mail: redesementesportal_am@hotmail.com

(D) https://orcid.org/0000-0002-2921-4032

3 Agente de comercialização externa da Rede de Sementes do Portal da Amazônia (RSPA), Cuiabá, MT. E-mail: marciocomunik@gmail.com.

(D) https://orcid.org/0000-0002-9335-2317

4 Engenheira-agrônoma, M. Sc. em Engenharia Agrícola, professora da Universidade do Estado de Mato Grosso (Unemat), Cuiabá, MT. E-mail: aluisamt@gmail.com.

(iD https://orcid.org/0000-0003-3825-7445

5 Engenheiro-agrônomo, D. Sc. em Engenharia Agrícola, professor da Universidade do Estado de Mato Grosso (Unemat), Cuiabá, MT. E-mail: roboredo@unemat.br.

(iD) https://orcid.org/0000-0002-7365-6807
} 
a preservação de serviços ecossistêmicos, garantindo a biodiversidade no território Portal da Amazônia, contribui também para o incremento da renda dos agricultores/coletores. Porém possui desafios que precisam ser superados para fortalecer a rede, entre eles merece destaque a incerteza quanto a continuidade de recursos financeiros para o acompanhamento da rede e a manutenção dos encontros entre seus integrantes.

Palavras-chave: sistemas agroflorestais, serviços ambientais, desenvolvimento, sustentável.

\title{
THE AMAZON PORTAL SEED NETWORK (RSPA): FROM SEED COLLECTION TO CONTRIBUTIONS TO ENVIRONMENTAL SERVICES
}

\begin{abstract}
Agricultural and forest seeds can be considered the main resource for the implementation of agroforestry systems (SAFs), which contribute to the generation of income for farmers / collectors through the commercialization of seeds and the implementation of more diversified systems that, in addition to the generation of products such as wood, fibers, seeds, food, also brings collectors and their families closer to nature, valuing the forest in the economic and social context, favoring the maintenance of biodiversity. In order to promote the implementation of the Forestry Agroforestry Systems project, in municipalities in the northern region of Mato Grosso, in 2010 the Amazonas Portal Seeds Network (PASB) was created. This article aims to present and analyze the work that the Portal da Amazônia Seed Network has been developing in the northern region of the state of Mato Grosso. As a result, it was found that the Amazonas Seeds Network contributes directly and indirectly to the preservation of ecosystem services, guaranteeing biodiversity in the Portal da Amazônia territory, as well as contributing to the increase of farmers '/ collectors' income. However, it has challenges that need to be overcome in order to strengthen the Network, among which it is worth mentioning the uncertainty regarding the continuity of financial resources for monitoring the Network and maintaining meetings between its members.
\end{abstract}

Keywords: agroforestry systems, environmental services, development, sustainable.

\section{Introdução}

Os sistemas agroflorestais (SAFs) podem ser considerados excelente opção para conciliar a conservação da natureza e a produção agropecuária. De acordo com Gusmão et al. (2018), os SAFs são ecossistemas dinâmicos, principalmente nos anos iniciais, com grande diversidade de plantas que proporcionam diferentes resultados aos agricultores. Entre os resultados pode-se mencionar a geração de renda para agricultores/coletores por meio da comercialização das sementes e implantação de sistemas mais diversificados que, além da geração de produtos como madeira, fibras, sementes, alimentos, aproxima da natureza os coletores e suas famílias, valorizando a floresta no contexto econômico e social, favorecendo a manutenção da biodiversidade, como alimentos, renda, contato com a natureza, entre outros.

No processo de implantação dos SAFs, as sementes florestais podem ser consideradas o principal insumo para que esses sistemas de cultivo se tornem realidade. Com o propósito de fomentar a implantação de projeto de sistemas agroflorestais e sistemas agrossilvipastoris, para promover o desenvolvimento social e econômico de agricultores familiares em municípios da região norte de Mato Grosso, em 2010 foi criada a Rede Sementes do Portal da Amazônia (RSPA) com apoio de organizações não governamentais locais.

Schmitt (2011) define rede como a união de diversos grupos com ideias próprias e objetivos em comum, sendo que a articulação existente entre esses diferentes elementos tem o potencial de 
se traduzir tanto a força como a fragilidade das regiões rurais. Diante disso, entende-se que uma estrutura em rede permite maior atuação na sociedade, conseguindo agregar diferentes grupos e consequentemente obter resultados diversos.

Importante lembrar que o estado de Mato Grosso é um território que tem tido grande expansão agrícola mecanizada nos últimos anos, recebendo o título de "celeiro do país" pela sua convencional produção de grãos. Tendo em vista a expansão da fronteira agrícola em direção à Amazônia (MARTINS, 2009), a região norte desse estado, local em que a rede foi criada, é considerada uma das últimas fronteiras de expansão da produção de grãos, dividindo esse título com a região do Matopiba (fronteira entre os estados do Maranhão, Tocantins, Piauí e da Bahia).

Especialmente no caso da agricultura familiar é importante mencionar que estruturas comunitárias, como associações, escolas, igrejas, espaços comunitários de lazer, pequenos comércios e cooperativas, são consideradas importantes no processo de reprodução social dessa categoria social. Da mesma forma, merece destaque o trabalho em parceria com organizações não governamentais (ONGs) locais, estaduais, nacionais e internacionais que desenvolvem projetos na região e impulsionam o desenvolvimento rural sustentável.

Diante do exposto, o presente artigo teve como objetivos apresentar e analisar o trabalho que a Rede de Sementes do Portal da Amazônia vem desenvolvendo na região norte do estado de Mato Grosso.

\section{Metodologia}

Para chegar ao objetivo proposto no artigo ora apresentado foram utilizados métodos de pesquisa quantitativos e qualitativos.

De acordo com Minayo (1999), os métodos quantitativos e qualitativos se diferenciam não só pela sistemática própria de cada um, mas também pela forma de abordagem do problema, e acabam se complementando dentro de uma pesquisa. Richardson et al. (1999) afirmam que o método quantitativo caracteriza-se pelo emprego da quantificação, tanto nas modalidades de coleta de informações quanto no tratamento delas, desde as estatísticas mais simples, como percentual, média, desvio-padrão, às mais complexas, como coeficiente de correlação, análise de regressão, etc. Já o método qualitativo difere do quantitativo à medida que não emprega um instrumental estatístico como base do processo de análise de um problema, não tendo pretensão de numerar ou medir unidades ou categorias homogêneas (RICHARDSON et al., 1999).

Optou-se pela realização da coleta de dados junto às fontes de dados secundárias, que conceitualmente são as que se constituem em um agente intermediário entre o foco da análise e o pesquisador, ocorrendo "quando o pesquisador utiliza outras fontes" (VIEIRA NETO, 2004). Neste trabalho realizou-se pesquisa, no mês de junho de 2019, no banco de dados da Rede Sementes do Portal Amazônia, disponibilizado pelo responsável técnico e pelo agente de comercialização de sementes, assim como consulta aos diagnósticos já realizados dentro da rede e dos relatórios de esclarecimentos perante o Ministério da Agricultura, Pecuária e Abastecimento (Mapa). 


\section{Resultados e Discussão}

\section{O nascimento da Rede de Sementes do Portal da Amazônia (RSPA)}

A construção do conhecimento é um processo lento e árduo, principalmente quando se têm poucas informações sobre o assunto. Inicialmente, os primeiros desafios da rede foram conhecer as espécies que ocorriam na região, identificando aspectos como período de coleta, procedimentos de beneficiamento; como fazer a limpeza? como coletar? como avaliar sua qualidade e, finalmente, qual o preço justo pela semente? Com essas e outras perguntas se inicia a formação da RSPA, no ano de 2010, com 250 integrantes. O objetivo principal era garantir sementes para a implantação de projetos de Sistemas Agroflorestais (SAFs) e Sistemas Agrossilvipastoris que estavam sendo apoiados por ações de uma ONG local, o Instituto Ouro Verde (IOV).

Nesse contexto, no início dos trabalhos do IOV, com a implantação dos SAFs evidenciou-se um desafio para a região, o acesso a sementes de boa qualidade, tendo em vista que muitos agricultores já não armazenavam sementes agrícolas após a colheita para depois realizarem novo plantio. Da mesma forma, as sementes florestais eram de difícil acesso na região, devido ao pouco conhecimento sobre as espécies e nenhuma iniciativa de coleta.

Importante destacar que a rede foi criada com o apoio de recursos do Projeto Sementes do Portal, desenvolvido entre os anos de 2010 e 2013, e do Projeto Sementes do Portal/Fase II, desenvolvido entre os anos de 2014 e 2019. Ambos os projetos foram apoiados pelo Fundo Amazônia. Piletti et al. (2015) ressaltam que, por meio da cooperação, a humanidade sobreviveu desde o princípio até hoje e esta é uma forma de organização da sociedade. Deste modo, essa foi a forma de gestão do recurso adotada nesses projetos, sendo o recurso administrado pelo IOV e gerido em cooperação entre movimentos sociais (Comissão Pastoral da Terra e Movimento de Mulheres Camponesas) e associações locais de agricultores, em forma de conselhos locais nos municípios que definiam as ações para investimento.

Ressalta-se que entre as ações do Projeto Sementes do Portal/Fase II nas comunidades estava a recuperação de áreas degradadas, com modelos complementares aos sistemas produtivos da pecuária leiteira e a implantação de sistemas agroflorestais como sistemas produtivos. Essa ação contribuiu para que o Projeto Sementes do Portal fosse o principal mercado para a aquisição de sementes da rede. Entre os anos de 2010 e 2014, 100\% da comercialização de sementes era organizada pela RSPA e vendida individualmente pelos coletores, com a admissão de nota fiscal de produtos emitidas pela Secretaria de Estado da Fazenda (Sefaz) de Mato Grosso.

Ao longo de sua existência, a RSPA aprimorou seu objetivo inicial, passando a relacionar outros aspectos dentro do seu processo organizativo. Atualmente (2019), entre os objetivos, destacam-se:

I. Fornecer sementes de qualidade para implantação de sistemas agroflorestais.

II. Comercializar sementes.

III. Valorizar os produtos não madeireiros. 
IV. Ser uma ferramenta de articulação e troca de experiências.

Atualmente (2019), a RSPA conta com 120 coletores, sócios da Cooperguarita, sendo que desse total $46 \%$ são mulheres. A coleta de sementes vem representando uma fonte de renda para as mulheres e para composição da renda familiar, auxiliando a permanência na propriedade e contribuindo para a independência e autonomia da mulher, assim como para a segurança alimentar da família.

Os integrantes da rede apostam que a coleta de sementes florestais permite uma aproximação com a floresta. Estudo feito na RSPA aponta que $73 \%$ dos agricultores entrevistados acreditam que a atividade econômica da coleta de sementes auxilia na conservação da natureza (ANDRADE, 2018), o que assume especial importância, se considerar que os bens naturais (solo e florestas, principalmente) da região encontram-se em diferentes estágios de degradação, demandando ações de conservação.

Importante destacar que, na visão convencional local, a floresta é vista como um entrave ao desenvolvimento, o que explica a alta taxa de desmatamento na região ${ }^{6}$. Na RPSA a floresta é vista como essencial à vida humana. Conhecer as espécies, os usos possíveis, tanto como produtora de sementes quanto medicinal, recuperadora de solo, atrativa de fauna, entre outros usos permite criar uma nova percepção sobre a floresta, com a preservação das áreas nativas e plantio de novas áreas com os SAFs. Diante disso, na região do norte do estado de Mato Grosso, a rede de sementes é um espaço importante para a troca de conhecimento entre os grupos e um exercício de auto-gestão, decisão participativa e resolução de conflitos e nivelamento de informações, contribuindo para a construção do conhecimento agroecológico e a valorização dos conhecimentos tradicionais dos agricultores, assim como para o resgate e manutenção da biodiversidade local.

\section{Estrutura da Rede de Sementes do Portal da Amazônia}

A formação da rede de sementes tem por base a organização em cooperação nas comunidades, grupos de coletores, sendo cada um regido por regulamento específico. Os regulamentos são compreendidos como os acordos e compromissos que o coletor possui perante o grupo.

A rede está estruturada com dois elementos básicos: 1) os espaços físicos nas comunidades, denominados casas de sementes (CS); e 2) a gestão em grupo. Além disso, a rede conta com a figura de um responsável técnico com dedicação exclusiva, que realiza acompanhamento nas casas, conferindo a qualidade dos lotes de sementes e prestação de conta perante o Mapa, e um agente de comercialização, contratado para pesquisar mercados possíveis com ONGs, viveiros, iniciativas privadas de subprodutos de sementes, entre outros.

\section{Casas de Sementes (CS) e a gestão em grupo}

As casas de sementes (CS) são os espaços construídos para receber, classificar e armazenar as sementes coletadas, as quais também funcionam como ponto de encontro e planejamento das atividades. Atualmente, os coletores estão organizados em $13 \mathrm{CS}$ localizadas nas comunidades rurais, nos municípios mato-grossenses de Apiacás (01), Alta Floresta (03), Carlinda (02), Colíder

\footnotetext{
${ }^{6}$ Mais informações sobre o desmatamento na região podem ser obtidas em http://www.obt.inpe.br/OBT/assuntos/programas/ amazonia/prodes.
} 
(01), Nova Canaã do Norte (02), Nova Guarita (01) e Terra Nova do Norte (03). Em Nova Santa Helena, MT, há um grupo em processo de organização e por isso ainda não há casa de sementes. Na Figura 1 pode se observar a estrutura da rede de semente e a articulação das atividades.

Figura 1. Estrutura geral da Rede de Sementes do Portal da Amazônia (RSPA).

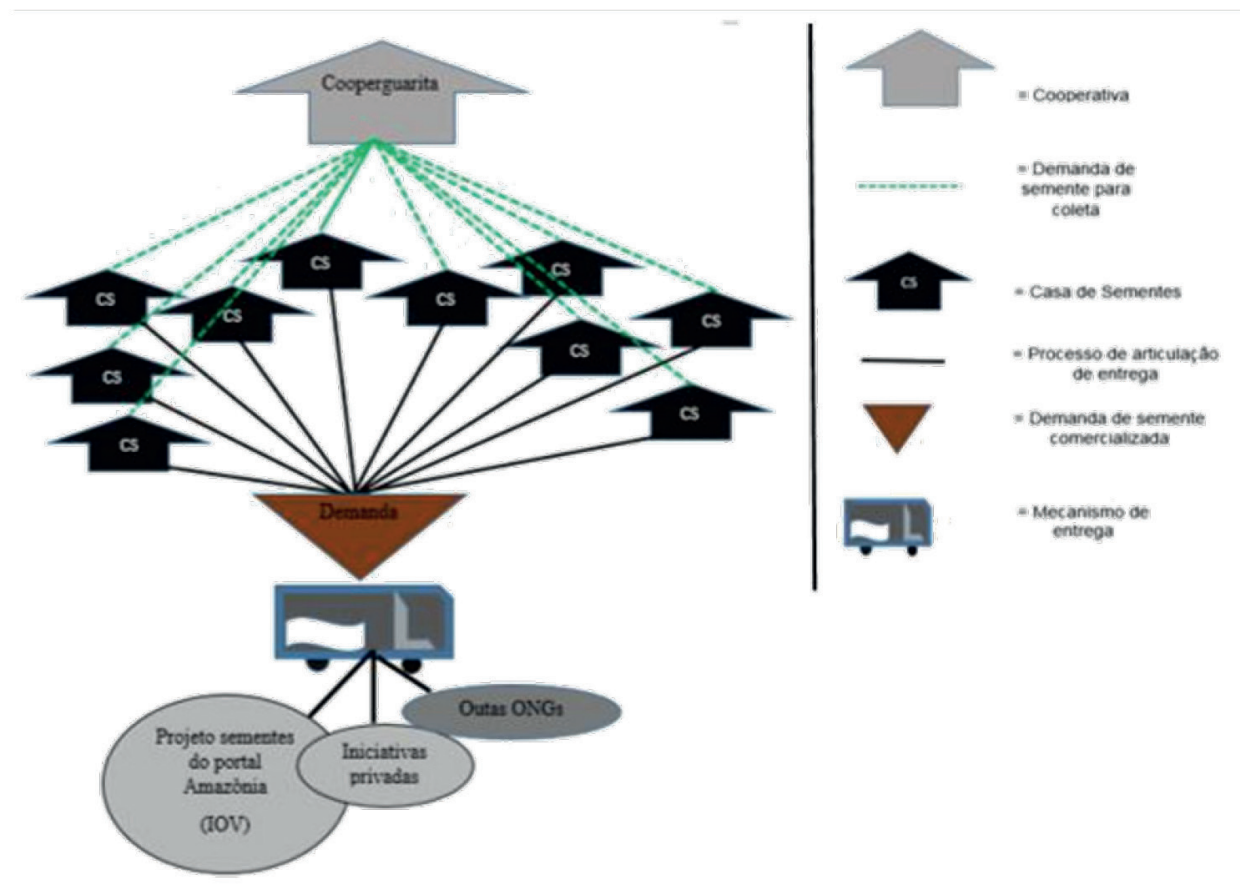

Fonte: Elaborada pelos autores

Cada CS possui um plano de gestão construído coletivamente dentro do grupo. Esse plano orienta todos os aspectos, como uso e manutenção dos equipamentos da casa, como serão custeadas as despesas, por exemplo, o pagamento de energia elétrica, contribuição financeira aos coordenadores, entre outros. Incentiva-se a criação de um fundo de reserva para gastos não planejados, como a quebra de algum equipamento ou possíveis reformas na construção do prédio.

Há grupos que escolhem um coordenador por certo período, e outros que dividem a coordenação em várias pessoas, dependendo da capacidade de gestão. $\mathrm{O}$ coordenador tem a função de animar os processos, convocando as entregas de sementes, acompanhar a classificação e o armazenamento e ajudar na distribuição das metas de coleta entre os coletores locais, articular a participação nas reuniões da rede com todos os outros integrantes das casas. De acordo com o grupo são definidos dias do mês para que todos os coletores do grupo possam entregar as sementes coletadas.

Todas as casas se reúnem em assembleia geral uma vez por ano para avaliação dos avanços e limitações da rede. Desta forma os principais temas trabalhados nesses encontros envolvem a indicação de demandas de pesquisa, estratégias de aperfeiçoamento na gestão dos processos e na qualidade das sementes, projeções de mercados futuros, ampliação da rede à criação de outros grupos. 
Além dos encontros gerais, uma vez por ano, são feitas reuniões periódicas entre as casas. Essas reuniões têm caráter formal de repasse de informações debatidas na assembleia, posicionamento do grupo em relação às metas estabelecidas e distribuição de sementes frente às solicitações de venda, bem como o acompanhamento do cumprimento das metas de coleta estabelecidas. As reuniões têm o apoio do responsável técnico (RT), que não interfere nas decisões dos grupos.

Atualmente (2019), para uma pessoa se cadastrar como coletora de sementes da rede, ela tem que ser maior de 18 anos ou emancipada, possuir inscrição estadual mencionando os itens propostos à venda e ter o Cadastro de Pessoa Física $(\mathrm{CPF})$ regularizado, seguir o plano gestor da casa, não deve entregar sementes de terceiro, a fim de cumprir sua demanda de coleta de semente, sem o consentimento da rede, podendo ser punido de acordo com o plano de gestão da casa.

A coleta das sementes é realizada pelos agricultores/coletores, que passam por um processo de formação por meio de assistência técnica, principalmente troca de experiências dentro da rede. As sementes são levadas para a CS já selecionadas e limpas. A avaliação da qualidade das sementes entregues é coletiva. Sementes com qualidade inferior são destinadas para um novo beneficiamento ou descartadas. Sementes classificadas como aptas são pesadas e armazenadas, rotuladas com nome popular, nome científico, lote, data da coleta e identificação da CS correspondente de acordo com o Registro Nacional de Sementes e Mudas (Renasem) seguindo a Lei no 10.711/03. As sementes ficam armazenadas até a data de entrega ao comprador.

\section{Indicadores de resultados da Rede de Sementes do Portal da Amazônia}

Conforme pode ser visualizado na Tabela 1, as quantidades produzidas/coletadas e comercializadas pela rede variaram ao longo do tempo. Conforme mencionado anteriormente, a Fase I do Projeto Sementes do Portal teve duração de 3 anos, entre 2010 e 2013, esse fato contribui para explicar o baixo volume comercializado no ano de 2013, uma vez que nesse ano não houve grande área de plantio de sementes agrícolas devido ao fim da etapa do projeto, com reflexos ainda no ano de 2014.

Tabela 1. Receitas e percentuais de venda da associação.

\begin{tabular}{|c|c|c|c|}
\hline \multirow{2}{*}{ Anos } & \multicolumn{3}{|c|}{ Produção de sementes (t) } \\
\hline & Quantidade Produzida & Quantidade Comercializada & Número de Coletores \\
\hline 2010 & 17.0 & 17.0 & 250 \\
\hline 2011 & 27.8 & 27.8 & 150 \\
\hline 2012 & 31.5 & 31.5 & 100 \\
\hline 2013 & 1.0 & 1.0 & 100 \\
\hline 2014 & 9.3 & 7.0 & 74 \\
\hline 2015 & 16.0 & 15.2 & 85 \\
\hline 2016 & 12.8 & 11.3 & 102 \\
\hline 2017 & 16.5 & 12.6 & 120 \\
\hline 2018 & 10.8 & 6.6 & 120 \\
\hline
\end{tabular}

Fonte: Dados da pesquisa fornecidos pela Rede Sementes do Portal da Amazônia. 
Com a aprovação do Projeto Sementes do Portal Fase II, entre 2014 e 2019, deu-se continuidade às atividades no projeto anterior, favorecendo a rede de sementes. Esse fato evidencia a importância do recurso do projeto apoiado pelo Fundo Amazônia na estruturação e manutenção da Rede de Sementes do Portal.

Ao longo dos anos, as estruturas da rede foram repensadas com o intuito de atingir outros mercados, além do Projeto Sementes do Portal, com a contratação de um agente de comercialização. Essas vendas são consideradas como "vendas externas" e que contribuiriam para aumentar a resiliência da RSPA.

Outra questão importante a ser observada é o número de coletores. Ao longo do tempo, observa-se que houve variação no número de integrantes da rede. Esse número veio a se estabilizar somente nos últimos dois anos, 2017 e 2018. Neste ponto é importante destacar que o cadastro como coletor da rede de sementes geralmente é de uma pessoa, porém, em muitos casos, toda a família se envolve nas etapas da produção de sementes, que vai da coleta, beneficiamento, secagem, seleção ao armazenamento, revelando que o número de pessoas diretamente envolvidas com a atividade de coleta de sementes pode ser bem superior a esse.

Entre os fatores que contribuíram para a variação no número de coletores pode-se destacar que, por ser uma atividade nova na região, a coleta de sementes não é a principal fonte de renda de muitos agricultores. Além disso, a coleta de sementes é concentrada em certo período do ano, a depender da época de produção de cada espécie, no entanto os coletores são agricultores e precisam de renda o ano todo, por isso desenvolvem concomitantemente outras atividades, como a pecuária, horticultura, piscicultura, entre outras.

Outro fator que contribuiu para a variação no número de coletores está ligado às normas sanitárias. Entre os anos de 2010 e 2014 foram identificadas implicações na legislação para a comercialização de sementes e legalização da atividade nos parâmetros do Ministério da Agricultura (Mapa), de acordo com os critérios em vigência do Renasem. Andrade (2018) chamou a atenção que, nos últimos anos, acentuaram-se os avanços na legislação no que diz respeito à coleta de sementes nativas. No caso da RSPA, a "legalização" da atividade nos termos das normas sanitárias trouxe empecilhos para alguns agricultores, sendo estes impossibilitados de exercer a atividade de coleta.

O Sistema Nacional de Sementes e Mudas (SNSM), instituído pela Lei $n^{\circ}$ 10.711/2003 (BRASIL, 2003), trouxe a diferenciação das sementes florestais nativas das sementes de espécies agrícolas. Por sua vez, o capítulo XXI do Decreto $\mathrm{n}^{0} 5.153 / 2004$ dispõe exclusivamente sobre as espécies nativas florestais, e a Instrução Normativa $n^{0}$ 56/2011 passou a regulamentar a produção, comercialização e a utilização de sementes e mudas de espécies florestais, nativas e exóticas. Essa última regulamentação representou consideráveis avanços para o setor florestal, especificamente para as redes de sementes florestais, reconhecendo a importância e valorizando essa atividade na sociedade.

No ano de 2016, com o objetivo de adequar-se a novos mercados, a RSPA foi formalizada junto a Cooperativa Agropecuária Mista de Nova Guarita (Cooperguarita), constituída desde 2005, no município de Nova Guarita, MT. Essa ação viabilizou a ampliação da comercialização 
de sementes para os mercados locais, assim como para fora do estado, outras ONGs e iniciativa privada, ampliando a contribuição da RPSA para a implantação, recuperação e conservação de ecossistemas essenciais para o fornecimento de serviços ambientais (Figura 2).

Figura 2. Sementes e sistemas agroflorestais implantados em área de recuperação e conservação de ecossistemas essenciais para o fornecimento de serviços ambientais.
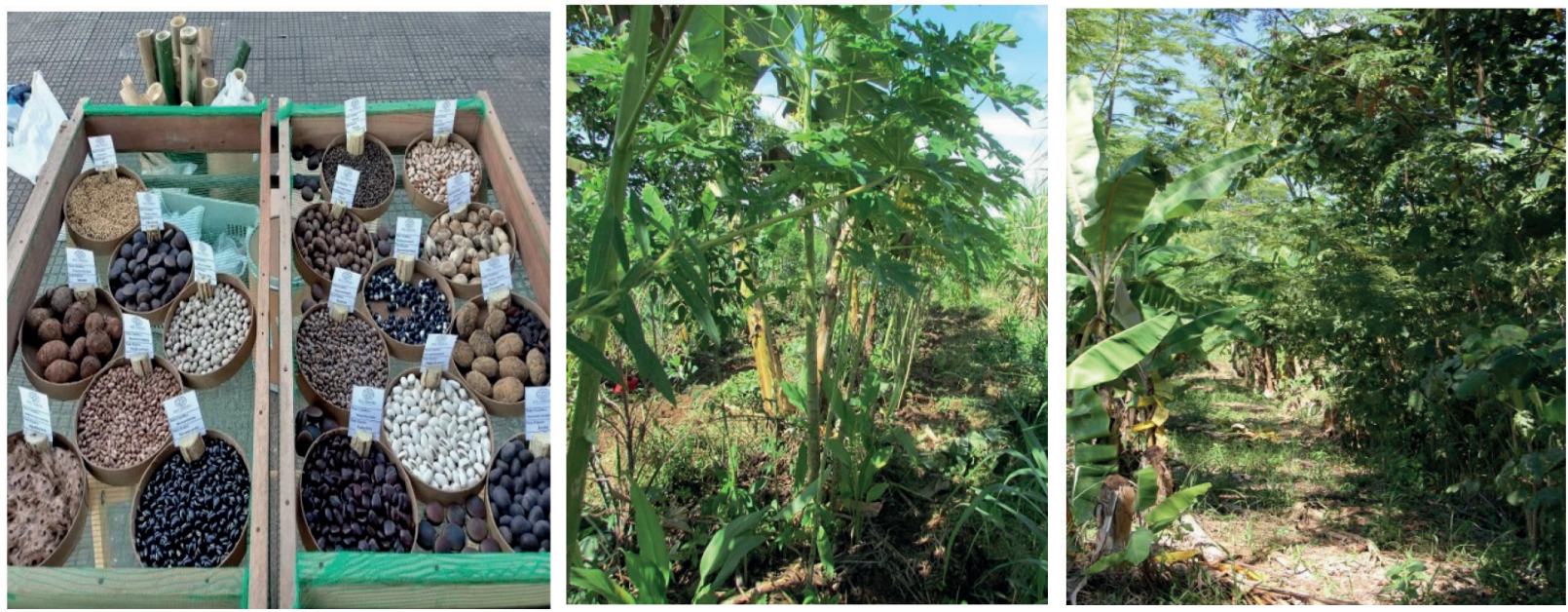

Fonte: Acervo da Rede Sementes do Portal da Amazônia (2019).

Em 2018, com a realização de pesquisas no território, foram identificadas, mapeadas e georreferenciadas 1.104 matrizes de espécies florestais em um período de três anos (2014 a 2017) (ANDRADE, 2018). Para identificação botânica das matrizes catalogadas foi realizada uma parceria com o Herbário do Campus Universitário de Alta Floresta, da Universidade do Estado de Mato Grosso (Unemat). A execução desse processo foi constituída por uma equipe composta de um identificador botânico e cinco estagiários da Universidade de São Paulo (USP) e da Unemat. Identificou-se que a rede trabalhava com mais de 150 espécies florestais e/ou agrícolas (Tabela 2) com diferente distribuição geográfica espacial.

Tabela 2. Número de espécies de sementes comercializadas pela Rede de Sementes do Portal da Amazônia (RSPA) entre 2010 e 2018.

\begin{tabular}{|lc|}
\hline Anos & Número de espécies \\
\hline 2010 & 134 \\
2011 & 183 \\
2012 & 168 \\
2013 & 93 \\
2014 & 141 \\
2015 & 158 \\
2016 & 176 \\
2017 & 156 \\
\hline 2018 & 154 \\
\hline
\end{tabular}

Fonte: Dados da pesquisa fornecidos pela Rede Sementes do Portal da Amazônia. 
A Tabela 3 demonstra os dados do volume de sementes comercializado e valor recebido por casa de semente, entre os anos de 2014 e 2018. Esse insumo foi destinado à implantação de SAF nos mais diversos locais, principalmente nos municípios em que se encontram ações do Projeto Sementes do Portal.

Os dados entre 2010 e 2013 não foram apurados de forma descritiva, por isso é um dado ausente na Tabela 3. No entanto, essa tabela diagnostica o potencial de coleta e a economia gerada nos municípios, fato que contribui para afirmar a importância do projeto na história da rede de sementes e a necessidade de avançar e ampliar as possibilidades de comercialização de sementes, não só para o plantio e recuperação de áreas degradadas, mas também para produção de cosméticos, medicamentos, artesanatos, entre outras finalidades.

Tabela 3. Coleta de sementes e renda na Rede de Sementes do Portal da Amazônia (RSPA), entre 2014 e 2018, com comercialização direta ao Projeto Sementes do Portal - Fase II.

\begin{tabular}{|cccc|}
\hline Casca & $\begin{array}{c}\text { Quantidade Coletada } \\
(\mathrm{t})\end{array}$ & $\begin{array}{c}\text { Quantidade Comercializada } \\
(\mathrm{t})\end{array}$ & $\begin{array}{c}\text { Valor recebido } \\
(\mathbf{R} \$)\end{array}$ \\
\hline Apiacás & 2.7 & 2.3 & $34.964,12$ \\
\hline Rondon & 3.2 & 2.4 & $38.092,07$ \\
\hline São Mateus & 2.1 & 1.6 & $39.128,57$ \\
\hline Estrela do Sul & 1.8 & 1.6 & $39.137,33$ \\
\hline Nazaré & 3.0 & 2.5 & $42.616,06$ \\
\hline São José & 2.6 & 1.8 & $56.049,13$ \\
\hline Santa Lúcia & 2.8 & 2.3 & $61.827,68$ \\
\hline Colíder & 4.4 & 3.6 & $79.308,29$ \\
\hline PDS & 7.9 & 5.8 & $104.483,27$ \\
\hline Veraneio & 14.1 & 8.4 & $155.652,79$ \\
\hline Terra Nova 1 & 10.1 & 8.0 & $210.375,29$ \\
\hline Nova Guarita & 10.4 & 8.2 & $214.673,46$ \\
\hline Total & 65.0 & 48.5 & $1.076 .308,05$ \\
\hline
\end{tabular}

Fonte: Dados da pesquisa fornecidos pela Rede Sementes do Portal da Amazônia.

A Tabela 4 apresenta os valores obtidos com a comercialização externa entre os anos de 2014 e 2018, por casa de semente. Importante destacar que o valor recebido se converte em renda para os agricultores/coletores e é adicionado à economia local, contribuindo para o fortalecimento desta nos municípios em que há casas de sementes.

Outro dado interessante a ser observado é que, em 2018, das 154 espécies que foram comercializadas, há destaque para as 25 espécies com potencial para vendas externas, as quais são apresentadas na Tabela 5. Entre essas, Ormosia grossa, popularmente conhecida como olho-de-cabra, aparece como a que possui maior potencial, sendo a espécie com maior quantidade comercializada, o que reflete em maior valor recebido. 
Tabela 4. Comercialização externa por casa de sementes da Rede de Sementes do Portal da Amazônia (RSPA), entre 2014 e 2018.

\begin{tabular}{|cc|}
\hline Casa de Semente & Valor recebido (R\$) \\
\hline Apiacás & $2.523,29$ \\
Estrela do Sul & $14.660,65$ \\
Santa Lúcia & $9.029,14$ \\
São Mateus & $6.442,85$ \\
PDS & $9.950,40$ \\
Rondon & $5.495,51$ \\
Veraneio & $22.721,24$ \\
Colíder & $9.412,91$ \\
Terra Nova & $26.408,31$ \\
Nazaré & $4.350,84$ \\
Frei Galvão & $15.640,91$ \\
Santa Helena & $1.500,00$ \\
\hline
\end{tabular}

Fonte: Dados da pesquisa fornecidos pela Rede Sementes do Portal da Amazônia.

Tabela 5. Comercialização externa, por espécies de semente, da Rede de Sementes do Portal da Amazônia (RSPA), entre 2014 e 2018.

\begin{tabular}{|c|c|c|c|}
\hline Nome científico & Nome popular & $\begin{array}{l}\text { Quantidade comercializada } \\
\text { (kg) }\end{array}$ & $\begin{array}{l}\text { Valor recebido } \\
\text { ( } R \$)\end{array}$ \\
\hline Ormosia grossa & Olho-de-cabra & $1.927,80$ & $40.102,63$ \\
\hline Dipteryx odorata & Champanhe & $1.313,10$ & $6.720,88$ \\
\hline Bactris gasipaes & Pupunha & 253,30 & $6.565,50$ \\
\hline Canavalia ensiformis & Feijão-de-porco & 570,10 & $5.707,20$ \\
\hline Swietenia macropylla & Mogno & 15,40 & $4.580,00$ \\
\hline Cedrela fissilis & Cedro-rosa & 19,32 & $4.173,12$ \\
\hline Enterolobium timbouva & Timburi & 35,20 & $3.280,96$ \\
\hline Caryocar brasiliense & Pequi & 77,00 & $2.975,00$ \\
\hline Diospyros hispida & Caqui-do-mato & 70,46 & $2.969,51$ \\
\hline Hymenaea courbaril & Jatobá & 149,20 & $2.627,60$ \\
\hline Enterolobium schomburgkii & Orelinha & 18,08 & $2.583,24$ \\
\hline Buchenavia tomentosa & Mirindiba & 39,02 & $2.270,11$ \\
\hline Carica papaya & Mamão & 8,75 & $2.267,20$ \\
\hline Ceiba speciosa & Paineira-barriguda & 12,89 & $2.246,75$ \\
\hline Caryocar brasiliense & Bordão-de-velho & 18,64 & $2.213,72$ \\
\hline Schizolobium parahyba & Pinho-cuiabano & 89,70 & $2.132,13$ \\
\hline Colubrina glandulosa & Som-brasil & 10,10 & $1.800,75$ \\
\hline Bixa arbórea & Urucum-do-brejo & 53,45 & $1.732,01$ \\
\hline Chloroleucon acacioides & Amarelinho & 16,75 & $1.612,95$ \\
\hline Spondias mombin & Cajazinho & 34,95 & $1.608,60$ \\
\hline Copaifera martii & Copaíba & 20,24 & $1.607,62$ \\
\hline Apeiba tibourbou & Pente-de-macaco & 16,63 & $1.542,72$ \\
\hline Guazuma ulmifolia & Mutamba & 10,02 & $1.533,84$ \\
\hline
\end{tabular}

Fonte: Dados da pesquisa fornecidos pela Rede Sementes do Portal da Amazônia. 
Ressalta-se que, entre os anos de 2014 e 2018, as vendas externas atingiram um montante de mais 5,7 t, 136 vendas concretizadas de 121 diferentes espécies, o que representou um capital de R\$ 128.136,05 para a rede. Entre os anos de 2010 e 2018, os integrantes da rede coletaram 142,7 t e comercializaram 130 t de sementes, auxiliando na propagação genética, regeneração da diversidade florestal, garantindo a perpetuação de espécie em risco de extinção, da fauna em diversos âmbitos, resultando em serviços ambientais para a população.

Importante ressaltar que, como dito anteriormente, entre os anos de 2010 e 2018, o principal cliente foi o Projeto Sementes do Portal, tanto na Fase I como na Fase II. Esse recurso foi fundamental para a implantação da rede e das casas de sementes. No entanto, o que foi um ponto forte para a rede hoje é um ponto limitante. Conforme mencionado, o recurso desses projetos tem como origem o Fundo Amazônia, e com o encerramento da Fase II e as incertezas quanto à aprovação da Fase III (que será a continuidade das atividades da Fase II), não houve plantio de SAF em 2019 via projeto, o que vai refletir na redução da produção e consequentemente na disponibilidade e comercialização de sementes para outros mercados.

\section{Desafios da Rede de Sementes do Portal da Amazônia}

Conforme visto ao longo da sua história, a RSPA foi se modificando e se aprimorando, tanto tecnicamente quanto na sua capacidade de gestão. Muitas dificuldades foram superadas, como a legalização da rede de sementes nos órgãos oficiais do País. Porém alguns desafios continuam presentes:

I. As incertezas quanto à aprovação da Fase III do Projeto Sementes do Portal.

II. Os grupos de coletores têm dificuldade de se reunirem nos encontros ampliados da rede de sementes pelas longas distâncias entre os municípios.

III. Muitos grupos ainda necessitam de acompanhamento técnico para coleta, identificação e armazenamento das sementes com o objetivo de garantir uma ótima qualidade das sementes.

IV. Alguns grupos ainda possuem dificuldades de gestão interna e necessitam de um acompanhamento mais intensivo para sua organicidade e resolução de conflitos.

V. Parte das espécies coletadas pela rede ainda não está cadastrada no Mapa por falta de laboratórios especializados na classificação dessas espécies na região.

\section{Considerações Finais}

A Rede de Sementes do Portal da Amazônia assumiu grande importância como estratégia de organização e resistência da agricultura familiar na região, permitindo a organicidade de vários grupos antes desconectados, diversificando a renda das famílias, garantindo os insumos necessários para implantação dos sistemas agroflorestais e reconectando as famílias com a floresta. Esses elementos são de fundamental importância para a resiliência da agricultura familiar e camponesa enquanto visão de mundo e forma de ocupação do território, assim como para o resgate, manutenção e conservação da biodiversidade local e o fornecimento de serviços ambientais. 
Ao longo do tempo, muitas dificuldades foram superadas, como legalização da rede de sementes nos órgãos oficiais do País de controle e fiscalização. Porém, há diversos desafios que precisam ser superados para a continuidade desse trabalho que vem fazendo a diferença na região norte de Mato Grosso. Entre os desafios merecem destaque as incertezas quanto à aprovação da Fase III do Projeto Sementes do Portal, que permite o acompanhamento da rede e a manutenção dos encontros entre seus integrantes, que vem contribuindo de forma expressiva para a sustentabilidade do espaço rural.

A garantia do recurso tem fundamental importância para o acompanhamento técnico para coleta, identificação e armazenamento das sementes com o objetivo de garantir uma ótima qualidade das sementes, que vai refletir no sucesso no momento da implantação dos sistemas agroflorestais mais diversos.

\section{Referências}

ANDRADE, M. Da semente à comercialização: a produção de sementes florestais no Território do Portal da Amazônia. 2018. 75 f. Trabalho de Conclusão de Curso (Graduação em Engenheira Florestal Licenciada em Ciências Agrárias) - Universidade de São Paulo Escola Superior de Agricultura "Luiz de Queiroz", Piracicaba.

BRASIL. Lei $n^{\circ} 10.711$, de 5 agosto de 2003. Diário Oficial da União, ago. 2003. Disponível em: http:// www.planalto.gov.br/ccivil_03/LEIS/2003/L10.711.htm. Acesso em: 29 abr. 2019.

GUSMÃO, M.; MORETTI, S. D. A.; MODRO, A. F. H.; MAIA, E.; SANTOS, C. M. M.; SANTANA, E. S. Caracterização de sistemas agroflorestais da zona da mata rondoniense. Cadernos de Agroecologia, v. 13, n. 1, 2018.

MARTINS, J. S. Fronteira: a degradação do outro nos confins do mundo. São Paulo: Contexto, 2009. $187 \mathrm{p}$.

MINAYO, M. C. S. O desafio do conhecimento: pesquisa qualitativa em saúde. 6. ed. São Paulo: Hucitec, 1992. $269 \mathrm{p}$.

PILETTI, D.; BORGES, G. R.; RASIA, I. C. R. B. Os princípios do cooperativismo e o trabalho em equipe em cooperativas de Garibaldi-RS. Navus - Revista de Gestão e Tecnologia, v. 5, n. 4, p. 34-45, 2015.

RICHARDSON, R. J. Pesquisa social: métodos e técnicas. São Paulo: Atlas, 1999. 334 p.

SCHMITT, C. J. Redes, atores e desenvolvimento rural: perspectivas na construção de uma abordagem relacional. Sociologias, v. 13, n. 27, p. 82-112, 2011.

VIEIRA NETO, P. Estatística descritiva: conceitos básicos. 2004. Disponível em: http://uni.educacional. com.br/up/59960001/3103751/Apos_Est_I_Fev04_C1.pdf. Acesso em: 17 set. 2019. 
